\title{
Influence of Peer Pressure on Sexual Behavior of Undergraduates in Kwara State
}

\section{Lateef Omotosho Adegboyega}

$\mathrm{PhD}$. Department of Counsellor Education, Faculty of Education, University of Ilorin, Ilorin, Nigeria, adegboyega.lo@unilorin.edu.ng

Victoria Abake Ayoola

Department of Counsellor Education, Faculty of Education, University of Ilorin, Ilorin, Nigeria

\section{Shuaib Muhammed}

PhD. Department of Counsellor Education, Faculty of Education, University of Ilorin, Ilorin, Nigeria

\begin{abstract}
Sexual development of the youth has increased in the society and public health concerns of all involved. This study investigated the influence of peer pressure on sexual behavior of undergraduates in Kwara State. Descriptive research design was adopted for the study as well as multi stage sampling procedure. A total of 395 undergraduates participated in the study, four research questions were generated to guide the conduct of the study, while three null hypotheses were formulated and tested at 0.05 level of significance. The instrument used for data collection for this study was a researchers-designed and structured questionnaire entitled "Influence of Peer Pressure Questionnaire" (IPPQ). The findings revealed that the influence of peer pressure on sexual behavior of undergraduates reveals that it leads students to erotic electro-stimulation, prostitution, risk of contracting Sexually Transmitted Diseases (STD) and involvement in incest. There were no significant differences in the influence of peer pressure on sexual behavior of undergraduates in Kwara State based on gender and age. There was a significant difference in the influence of peer pressure on sexual behavior of undergraduates in Kwara State based on university attended. It was therefore recommended, among others that counsellors should enlighten the students on how peer pressure could be used to channel the students' behavior towards positive activities, counsellors should inform the students about the positive and negative influence of peer pressure to enhance self-esteem and social skills rather than for abusive purposes to students of different gender and age and counsellors should look for underlying issues that may have led to exhibition of risk sexual behavior through peer pressure and try to identify the perpetrators so that the victims could be offered counselling on assertiveness skills, socialization skills and improving self-concept.
\end{abstract}

Keywords: influence, peer pressure, sexual behavior, undergraduates, Kwara state

\section{INTRODUCTION}

Sexual development of the youth has increased in the society and public health concerns of all involved. This is because of the increased access to various media by the youth leading to higher consumption of television programs and information (Braun-Courville \& Rojas, 2009). Smith (2009) stated that one area of life in which the decline of traditional values is obvious is in the area of sexuality. One major change has been the acceptance of pre-marital sex in a loving relationship. Sexual relationship is on increase and common in most of Africa schools (Jones \& Espey, 2008). The trend is gradually changing and the incidence of student-adolescents' or youths' engaging in sexual

Citation: Adegboyega, L. O., Ayoola, V. A., \& Muhammed, S. (2019 Influence of Peer Pressure on Sexual Behavior of Undergraduates in Kwara State. Anatolian Journal of Education, 4(1), 49-58. https://doi.org/10.29333/aje.2019.415a 
relationship is high and may constitute problems including social, health and academic. Students' sexual activity has resulted into increased cases of unplanned pregnancies, poor academic performance, and eventually school dropouts (Mlyakado, 2013).

Risk taking is common and expected in adolescence. Across the lifespan, adolescence is the time of greatest risk taking (Chick \& Reyna, 2012). While understanding or even over-estimating the likelihood that an action will result in harm, adolescents may place higher value on the benefits that might come from taking a particular risk. Adolescents are more responsive to the rewards of risk (such as peer approval), may be less sensitive to feeling the ill effects of substance use (such as hangovers), and are still developing the capacities for judgment and self-control (Institute of Medicine [IOM] \& National Research Council [NRC], 2011).

Cohabitation among undergraduates of opposite sex is a predisposing factor to the initiation of sexual activities (Ogungbamila, 2013). Cohabitation results in two independent people almost like roommate, who are sexually involved, instead of being committed to one another for the rest of their lives (Rena, 2013). Cohabiting students will often engage in unprotected sex which could result to sexually transmitted infections and the much-dreaded HIV/AIDS diseases (Ogunsola, 2011). According to Arisukwu (2013), cohabitation has serious health effect on the female students who may indulge in the use of oral contraceptive in order to avoid unwanted pregnancy which may truncate their educational aspirations. Should pregnancy occur, such female students are more likely to seek abortion as an alternative (Arisukwu, 2013). This has serious health challenges for such students who may visit quack doctors and medical practitioners without adequate experiences and qualifications.

Another factor which can influence adolescent's sexual behavior is peer pressure. Peer pressure is the influence on an individual who gets encouraged to follow others by changing their attitudes, values or behavior to conform with those of the influencing group or individual either positively or negatively. A peer could be any one you look up to in behavior or someone who you would think is equal to your age or ability (Hardcastle, 2012). On the other hand, the term pressure implies the process that influence people to do something that they might not otherwise choose to do. Children try to get in touch with their peers as early as the age of seven (Muratore, 2008).

Adolescent influence begins at an early age and increases through the teenage years, it is natural, healthy and important for adolescent to have and rely on friends as they grow and mature. Student's communication patterns are initially affected by their experiences within the family of origin. However, upon reaching adolescence and then young adulthood, peers have increasing influence on their attitudes, beliefs, and behaviors. As college students develop greater autonomy from their family of origin, peer influence becomes even more important. Adolescents are particularly susceptible to influence from their friends because of the considerable attitudinal and behavioral similarity between them and their friends (Powell \& Segrin, 2009). The main sources of information used by children concerning all kinds of products come mainly from peers. Consumers tend to interact with peers about consumption matters, which greatly influence their attitudes toward products and services (Wang, Chunling \& Yujie, 2012). It is understandable that the preferences of children and teenagers towards products and brand names are influenced by peers (Muratore, 2008). Peers exert influences in written messages, such as positive and negative reviews, comments, suggestions, discussions, or experiences (Wang et al., 2012)

Mature adults, teens, young adults and children can be seen doing things in order to be accepted by their peers. Peer pressure is commonly associated with episodes of adolescent risk taking (such as delinquency, drug abuse, sexual behaviors), because these behaviors commonly occur in the company of peers. It can also have positive effects when youth are pressured by the peer toward positive behavior. Such as volunteering for charity or excelling in academics (Kellie, 2013). However, peers can also have a negative influence. They can encourage each other to skip classes, steal, cheat, use of 
drugs or alcohol, or become involve in other risky behaviors. Majority of adolescents with substance abuse problems began using drug or alcohol as a result of peer pressure. Negative peer pressure may influence in various ways like joining group who drink alcohol, smoke cigarette and Indian hemp among others. It may also lead to the decision to have a boyfriend /girlfriend, Peer pressure indulges youth into loitering about in the streets, watching films and attending parties during school hours, taping as alternative to stealing which may eventually graduate into armed robbery. (Arief, 2011)

Peer pressure was observed as a primary contextual factor contributing to adolescent's tendency to make risky decisions, (Steinberg \& Monahan, 2007). Gradually, children discover that others can share their feelings or attitudes or have quite different ones. The perspectives of others will affect how children feel about their own families. Children usually have a family view of their own and of other cultures. So, when confronted with other perspectives, they often need to rethink their own viewpoints. It is often difficult for children to adjust to the idea that other families can function radically differently from their own and yet hold many of the same attitudes and beliefs and be equally nurturing and secure. The peer group serves as a barometer for children examining themselves and their feelings about self and family.

However, the common belief is that during the time of adolescence, an important shift of influence occurs and peers begin to become increasingly more influential than parents (Moore \& Rosenthal, 2006). Adolescents start to accept their friends' attitudes about sexual permissiveness or lack thereof, and use these attitudes as a guide to their own sexual behaviors (Moore \& Rosenthal, 2006). This trend can be seen through a study conducted by Moore and Rosenthal; 69 percent of the sexually active young people reported that they felt comfortable discussing sexual concerns with their friends, while only 15 to 30 percent felt comfortable discussing these same concerns with their parents (Moore \& Rosenthal, 2006). Furthermore, this influential shift might occur in terms of a teen's sexual behavior because it has been seen that 61 percent of sexually active young people report that a large amount of their sexual education came from discussions with friends only, with no mention of either parent (Moore \& Rosenthal, 2006). Thus, these teens could be persuaded by their friends' discussions and usually inaccurate teachings about sexual behavior. Therefore, due to the peer pressure to engage in and talk about sex, males will expectantly have a much lower age of sexual initiation. This idea is parallel to the theory of reasoned action. The theory argues that perceived attitudes and perceived values/expectations of others have an important effect on an individual's own actions (Gillmore, Archibal, Morrison, Wilsdon, Elizabeth \& Marilyn, 2002).

According to Berk (2005), peer group also influences development of adolescents' socializing skills. These early friendships help adolescents learn how to negotiate and relate to others, including their siblings and other family members. They learn from peers how to cooperate and socialize according to group norms and group-sanctioned modes of behavior. The peer group can influence what the child values, knows, wears, eats and learns.

Adolescents' perception of the behavior and attitudes of their peers represents a particularly interesting field of research. The perception of their peers on the subject of sexual behaviors is an important normative predictor of intention (Hollander, 2010) with regard to the beginning of sexual relations and engaging in sexuality (Prinstein, Meade \& Cohen, 2013; Sieving, Eisenberg \& Pettingell, 2011) including oral sex (Halpern, Kropp \& Boyer 2014). However, peers can also have a positive influence by enticing youths to apply contraceptive measures and to use condoms for protection against STIs (Lagana, 2009)

Peer pressure has a lot of negative influence on students than the positive influence. Peer pressure to engage in adult-like activities can encourage adolescents to engage in various levels of sexual experimentation (Olugbenga, Adebimpe \& Abodurin 2009). Adolescents who engage in sexual experimentation are at increased risk for sexually transmitted infections, including HIV/AIDs, 
pregnancy and abortions. Teenage mothers suffer a lot of complications during delivery which in most cases result in high morbidity and mortality for both mother and infants. Peer pressure can make students to be involved in risky sexual behaviors like gang rape, unwanted pregnancy, abortions etc.

\section{Research Questions}

The following research questions were raised to guide the conduct of the study:

1. Does peer pressure influence the sexual behavior of undergraduates in Kwara State, Nigeria?

2. Is there any difference in the influence of peer pressure on sexual behavior of undergraduates in Kwara State based on gender?

3. Is there any difference in the influence of peer pressure on sexual behavior of undergraduates in Kwara State based on age?

4. Is there any difference in the influence of peer pressure on sexual behavior of undergraduates in Kwara State based on university attended?

\section{Hypotheses}

The following null hypotheses were formulated and tested in the study:

1. There is no significant difference in the influence of peer pressure on sexual behavior of undergraduates in Kwara State based on gender.

2. There is no significant difference in the influence of peer pressure on sexual behavior of undergraduates in Kwara State based on age.

There is no significant difference in the influence of peer pressure on sexual behavior of undergraduates in Kwara State based on university attended.

\section{METHOD}

The design that was adopted for this study is the descriptive survey research method. The researcher considered the descriptive survey design method most appropriate because it entails the use of direct observation in the collection of data which was employed in finding out the influence of peer pressure on sexual behavior of undergraduates' in Kwara State, Nigeria.

The population of the study consisted of all undergraduate students in universities in Kwara State while the target population was undergraduate students drawn from four (4) Universities in Kwara State, Nigeria. The population of undergraduate students at University of Ilorin is estimated at 35,336 (Academic Planning Unit, 2015/2016 session); Kwara State University, 8,685 (Academic Planning Unit, 2016/2017 session); Al-Hikmah University, 3000 (Academic Planning Unit, 2016/2017 session) and Landmark University, 3500 (Academic Planning Unit, 2016/2017 session). There are 50,521 undergraduates in Kwara State. According to the Research Advisor (2006), the minimum sample size for this population is 381, under $95 \%$ confidence level and at 5.0\% error margin. However, the researcher decided to increase this figure by $5 \%$ which brought the sample size to 400 , in order to ensure fair representation and cater for any attrition during the course of the administration.

Multi-stage sampling procedures were used in selecting the respondents for the study. Purposive, proportional and stratified random sampling methods were used to select 400 respondents from four (4) universities in Kwara State. In order to obtain the required sample for the study; at the first stage, purposive sampling was used to select four (4) universities. University of Ilorin, Ilorin; Al-Hikmah University, Ilorin; Kwara State University, Malete and Landmark University, OmuAran. The other two Universities, which were Crown Hill University and Summit University were newly established and were yet to develop student's culture and will not form part of the sample.

At stage two, proportional sampling was used to select 400 students in the ratio 20:5:2:2, in line with the magnitude of the universities' population. For University of Ilorin 279 respondents; Kwara State University 69 respondents; Landmark University 28 respondents; Al-Hikmah University 24 
respondents. Therefore, a total number of 400 respondents were selected from four (4) universities. At stage three, stratified random sampling technique was used to stratify respondents on the bases of their gender, age and university attended.

The instrument that was used for the collection of data was a self-developed questionnaire entitled "Influence of Peer Pressure Questionnaire" (IPPQ). The questionnaire consists of fifteen (15) items on influence of peer pressure on sexual behavior of undergraduates respectively. The questionnaire was divided into two sections; A and B. Section A elicits information on the personal data of respondents such as gender, age and university attended; Section B contains 15 items on the influence of peer pressure on sexual behavior of undergraduates.

The questionnaire was patterned in the form of a four-point Likert-type rating scale of SA (Strongly Agree); A (Agree); D (Disagree); and SD (Strongly Disagree). The questionnaire was validated by experts in counselling while the reliability of the questionnaire was determined through test re-test method. The set of scores were subjected to Pearson's Product Moment Correlation and a reliability co-efficient of 0.76 was obtained, indicating that the instrument is reliable for use.

The researchers employed both descriptive and inferential statistics for the data analysis. Percentages were used for the descriptive statistics while t-test and Analysis of Variance (ANOVA) statistical tools were employed to test the research hypotheses at 0.05 level of significance.

\section{FINDINGS}

Research Question: Does Peer Pressure Influence the Sexual Behavior of Undergraduates in Kwara State, Nigeria?

Table 1

Mean and Rank Order Analysis of the Influence of Peer Pressure on Sexual Behavior of Undergraduates in Kwara State

\begin{tabular}{llrc}
\hline Item No. & Peer pressure leads students into: & Mean & Rank \\
\hline 3 & erotic electro-stimulation & 3.22 & $1^{\text {st }}$ \\
2 & Prostitution & 3.20 & $2^{\text {nd }}$ \\
7 & contracting STDs & 3.17 & $3^{\text {rd }}$ \\
1 & involvement in incest & 3.16 & $4^{\text {th }}$ \\
5 & sexual intimidation & 3.16 & $4^{\text {th }}$ \\
6 & involvement in risky sexual behavior & 3.15 & $6^{\text {th }}$ \\
4 & erotic spanking & 3.14 & $7^{\text {th }}$ \\
8 & involvement in groping & 3.11 & $8^{\text {th }}$ \\
12 & involvement in pre-marital sex & 3.07 & $9^{\text {th }}$ \\
9 & Masturbation & 3.06 & $10^{\text {th }}$ \\
10 & Homosexuality & 3.05 & $11^{\text {th }}$ \\
13 & having unintended unwanted pregnancy & 3.05 & $11^{\text {th }}$ \\
11 & involvement in rape & 3.03 & $13^{\text {th }}$ \\
14 & frotting & 2.90 & $14^{\text {th }}$ \\
15 & involvement in orgies & 2.86 & $15^{\text {th }}$ \\
\hline
\end{tabular}

Table 1 shows the mean and rank order analysis of response on influence of peer pressure on sexual behavior of undergraduates in Kwara State. The result on the table revealed that items 3, 2, 7, 1, 5 ranked as the top 5 items. Items 3 which states that peer pressure leads students to "erotic electrostimulation" ranked $1^{\text {st }}$ with a mean score of $3.22(32.2 \%)$, Items 3 which states that the peer pressure leads students to "erotic electro-stimulation" ranked $1^{\text {st }}$ with a mean score of $3.22(32.2 \%)$, items 2 which states that peer pressure leads students to "prostitution" ranked $2^{\text {nd }}$ with a mean score of $3.20(32 \%)$, items 7 which states that peer pressure students to leads "contracting STDs" ranked 3 rd with a mean score of $3.17(31.7 \%)$, items 1 and 5 which states that peer pressure leads students to "involvement in incest" and "sexual intimidation" ranked $4^{\text {th }}$ with a mean score of $3.16(31.6 \%)$. 
The result on the table further revealed that items 6 which states that peer pressure leads students to "involvement in risky sexual behavior" ranked $6^{\text {th }}$ with a mean score of $3.15(31.5 \%)$, items 4 which states that peer pressure leads students to "erotic spanking" ranked $7^{\text {th }}$ with a mean score of 3.14 $(31.4 \%)$, items 8 which states that peer pressure leads students to "involvement in groping" ranked $8^{\text {th }}$ with a mean score of $3.11(31.1 \%)$, items 12 which states that peer pressure leads students "involvement in pre-marital sex" ranked $9^{\text {th }}$ with a mean score of $3.07(30.7 \%)$, items 9 which states that peer pressure leads students to "masturbation" ranked $10^{\text {th }}$ with a mean score of $3.06(30.6 \%)$, items 10 and 13 which states that peer pressure leads students to "homosexuality" and "having unintended unwanted pregnancy" ranked $11^{\text {th }}$ with a mean score of $3.05(30.5 \%)$, items 11 which states that peer pressure leads students to "involvement in rape" ranked $13^{\text {th }}$ with a mean score of 3.03 $(30.3 \%)$, items 14 which states that peer pressure leads students to "frotting" ranked $14^{\text {th }}$ with a mean score of $2.90(29 \%)$, and items 15 which states that peer pressure leads students to "involvement in orgies" ranked $15^{\text {th }}$ with a mean score of $2.86(28.6 \%)$. Therefore, it can be concluded social media commonly leads students to erotic electro-stimulation, prostitution, contracting STDs, involvement in incest and sexual intimidation among others

\section{Hypotheses Testing}

In this study, three (3) null hypotheses were postulated and tested. The hypotheses were tested using ttest and ANOVA statistical methods at 0.05 level of significance. The results are presented thus:

Hypothesis One: There is no significant difference in the influence of peer pressure on sexual behavior of undergraduates in Kwara State based on gender.

Table 2

Means, Standard Deviations and t-value of Respondent's Influence of Peer Pressure on Sexual Behavior of Undergraduates based on Gender

\begin{tabular}{lrrrrrrr}
\hline Gender & N & \multicolumn{1}{c}{ Mean } & \multicolumn{1}{c}{ Std. Dev } & df & Cal. t-value & Critical t-value & p-value \\
\hline Male & 204 & 46.67 & 7.03381 & 393 & 0.975 & 1.96 & 0.330 \\
Female & 191 & 45.99 & 6.62888 & & & &
\end{tabular}

Table 2 shows the data on the means, standard deviations and t-value of respondent's influence of peer pressure on sexual behavior of undergraduates based on gender. The table shows that the calculated tvalue of 0.975 is less than the critical t-value of 1.96 (p-value $0.330>0.05$ level of significance) on this basis, the null hypothesis which states that there is no significant difference in the influence of peer pressure on sexual behavior of undergraduates in Kwara State based on gender was not rejected. This means that undergraduates of different gender do not differ in their perception of the influence of peer pressure on sexual behavior of undergraduates.

Hypothesis Two: There is no significant difference in the influence of peer pressure on sexual behavior of undergraduates in Kwara State based on age.

Table 3

ANOVA result showing the Difference in Response of Respondent's Influence of Peer Pressure on Sexual Behavior of Undergraduates based on Age

\begin{tabular}{lcccccc}
\hline $\begin{array}{l}\text { Sources of } \\
\text { Variance }\end{array}$ & $\begin{array}{l}\text { Sum of } \\
\text { Squares }\end{array}$ & df & $\begin{array}{l}\text { Mean } \\
\text { Squares }\end{array}$ & Cal. F-value & Crit. F-value & p-value \\
\hline Between Groups & 183.78 & 3 & 61.26 & 1.31 & 2.60 & 0.27 \\
Within Groups & 18253.07 & 391 & 46.68 & & & \\
Total & 18436.86 & 394 & & & & \\
\hline
\end{tabular}

Table 3 shows the data on the Analysis of Variance result showing the difference in response of respondent's influence of peer pressure on sexual behavior of undergraduates based on age. The table 
shows that the calculated f-value of 1.31 is less than the critical t-value of 2.60 (p-value $0.27>0.05$ level of significance). Therefore, the null hypothesis which states that there is no significance difference in the influence of peer pressure on sexual behavior of undergraduates in Kwara State based on age was not rejected. This means that undergraduates of different age range do not differ in their perception of the influence of peer pressure on sexual behavior of undergraduates.

Hypothesis Three: There is no significant difference in the influence of peer pressure on sexual behavior of undergraduates in Kwara State based on university attended

Table 4

ANOVA Result showing the Difference in Expression of Respondent's Influence of Peer Pressure on Sexual Behavior of Undergraduates based on University Attended

\begin{tabular}{lcccccc}
\hline Sources of Variance & Sum of Squares & df & $\begin{array}{l}\text { Mean } \\
\text { Squares }\end{array}$ & Cal. F-value & $\begin{array}{l}\text { Crit. F- } \\
\text { value }\end{array}$ & p-value \\
\hline Between Groups & 433.56 & 3 & 144.52 & $3.13^{*}$ & 2.60 & 0.02 \\
Within Groups & 18003.30 & 391 & 46.04 & & & \\
Total & 18436.86 & 394 & & & & \\
\hline
\end{tabular}

Table 4 shows the data on the Analysis of Variance result showing the difference in response of respondent's influence of peer pressure on sexual behavior of undergraduates based on university attended. The table shows that the calculated f-value of 3.13 is less than the critical t-value of $2.60(\mathrm{p}$ value $0.02>0.05$ level of significance). Therefore, the null hypothesis which states that there is no significant difference in the influence of social media on sexual behavior of undergraduates in Kwara State based on university attended was rejected. This means that undergraduates of different universities differ in their perception of the influence of social media on sexual behavior of undergraduates. Duncan Multiple Range Test (DMRT) was carried out as a post-hoc test to determine the magnitude of difference of respondents' expression in table 5.

Table 5

DMRT showing the Magnitude of Difference in the Expression of Respondent's on the Influence of Peer Pressure on Sexual Behavior of Undergraduates based on University Attended

\begin{tabular}{lllcc}
\hline Universities & Mean & $\mathrm{N}$ & Group & Duncan's Grouping \\
\hline ALHIKMAH & 45.68 & 24 & 1 & $\mathrm{~A}$ \\
UNILORIN & 45.79 & 275 & 2 & $\mathrm{~A}$ \\
LANDMARK & 46.71 & 28 & 3 & $\mathrm{~B}$ \\
KWASU & 48.52 & 68 & 4 & $\mathrm{C}$ \\
\hline
\end{tabular}

Table 5 shows the magnitude of difference in the expression of respondents on the influence of peer pressure on sexual behavior of undergraduates based on university attended. The information on the table reveals that group 1 and 2 respondents who attends Al-Hikmah University and University of Ilorin have slightly different mean score of 45.68 and 45.79 respectively but significantly differ from group 3 (Landmark University) and group 4 (Kwara State University) with mean of 46.71 and 48.52 respectively. The mean score of group 4 (Kwara State University) also differed significantly from other groups. Therefore, it can be concluded that respondents who attends Kwara State University contributed to the difference noted in the ANOVA table.

\section{DISCUSSION}

The finding of the study revealed that peer pressure could lead students to involvement in erotic electro-stimulation, prostitution, risk of contract Sexually Transmitted Diseases (STD's) and involvement in incest. The reason for this finding could be because it is very common for people to belong and be part of a group, as there is nothing wrong with having good friendships in our lives which is really important to our happiness. That desire to be part of a group and have good friends can put a lot of pressure on student to act in some negative ways. Students sometimes sees their peers as an 
ideal person and imitate every attitude they exhibit both negative and positive in other to maintain good relationship with their them, which makes them to see some of the risky sexual behavior their friends exhibit as a normal thing which is done by everyone. Some of the students practice risky sexual behavior in other to feel among their peers and some practice such behavior so that they will not be criticized by their peers. The result of this study is in line with the study conducted by Nwoke, Okafo and Nwankwo (2012) who carried out a study on socio-demographic correlates of sexual behaviors and have peer pressure significantly influenced the sexual behaviors of the adolescents. Various ages at first sexual intercourse significantly influenced their sexual behaviors and various age groups of the adolescents influenced the adolescents' sexual behaviors significantly.

Furthermore, adolescents develop the need for intimacy, loyalty and psychological closeness from their friends (Berk, 2003), and they believe that their friends understand them better than their families do. The closeness of these friendships tends to be more intimate, intense, open and honest and much value is placed on peer normative beliefs. Research has shown that peers can either pose a negative influence to compromise adolescent sexual health, or peer norms may also promote more sexually healthy behaviors (Smylie, Medaglia, \& Maticka-Tyndale, 2006).

Finding revealed that there was no significant difference in the influence of peer pressure on sexual behavior of undergraduates in Kwara State based on gender. This means that peer pressure has no influence on both male and female undergraduates. The finding of this study is similar with WernerWilson (2007) who noted that generally, adolescent males and females reported similar perceptions of peer pressure, but males were more likely to submit to peer influence. The result of this study may be due to the fact that students spend most of their time with their friends who are possibly of the same sex and sees their peers as their role model and imitate them especially when they do not see anything bad in the act.

Another finding revealed that there was no significant difference in the influence of peer pressure on sexual behavior of undergraduates in Kwara State based on age. This means that there is no difference in the influence that peer pressure has on different age groups of undergraduates. The finding of this study supports the finding of Kawaguchi (2004) who posited that peer effects or peer pressure is identified as a critical determinant, since the use of substance and risky sexual behavior are considered to be a highly social behavior. Consequently, substance and other risky behavior are introduced to peers through a social intermediary which is mostly people from the same age. The result of this study may be due to the fact that students spend most of their time with their friends who are possibly of the same age and sees their peers as their role model and imitate them especially when they do not see anything bad in the act.

Another finding revealed that there was a significant difference in the influence of peer pressure on sexual behavior of undergraduates in Kwara State based on university attended. This means that there is a difference in the influence that peer pressure has on different university attended by undergraduates. The finding of the study contradicts the study of Amsale and Yemane (2012) who posited that peer pressure is the most important factor associated with risky sexual behavior among school adolescents in Addis Ababa. The result of this study may be due to the fact that undergraduates differ from one another in Kwara State.

\section{CONCLUSION}

The study concluded that peer pressure influence student's sexual behavior negatively as it encourages them to get involve in erotic electro-stimulation, prostitution, risk of contracting sexually transmitted diseases (STDs), involvement in incest and sexual intimidation. Also, there were no significant differences in the influence of peer pressure on sexual behavior of undergraduates in Kwara State based on gender and age while there was a significant difference in the influence of peer pressure on sexual behavior of undergraduates in Kwara State based on university attended. 


\section{RECOMMENDATIONS}

Based on the findings of this study, it was recommended that:

1. Counsellors could enlighten the students on how peer pressure could be used to channel the students' behavior towards positive activities.

2. Counsellors could inform the students about the positive and negative influence of peer pressure to enhance self-esteem and social skills rather than for abusive purposes to students of different gender, age and religious affiliation.

Counsellors could look for underlying issues that may have led to exhibition of risk sexual behavior through peer pressure and try to identify the perpetrators so that the victims could be offered counselling on assertiveness skills, socialization skills and improving self-concept. Also, counsellor should provide adequate information on the negative and positive influence of peer pressure to students from different universities

\section{REFERENCES}

Amsale, C., \& Yemane, B. (2012). Peer pressure is the prime driver of risky sexual behaviors among school adolescents in Addis Ababa, Ethiopia. World Journal of AIDS, 2, 159-164.

Arief, G. I., \& Martin, A. J. (2011). Peer relationship and adolescents' academic and non-academic outcomes: Same-sex and opposite-sex peer effect and the role of school engagement. British Journal of Educational Psychology, 81, 183-206.

Arisukwu, O. C. (2013). Cohabitation among university of Ibadan undergraduate students. Research on Humanities and Social Sciences, 3(5), 185-192.

Berk, L. E. (2003). Child development $\left(6^{\text {th }}\right.$ ed). Massachusettes: Pearson Education, Inc.

Braun-Courville, N. \& Rojas, A. M. (2009). Human development, family behavior parenting, marriage and counselling skills. Enugu: Snapp Press Ltd.

Chick, C. F., \& Reyna, V. F. (2012). A fuzzy trace theory of adolescent risk taking: Beyond selfcontrol and sensation seeking. In V. Reyna, S. Chapman, M. Dougherty, \& J. Confrey (Eds.), The adolescent brain: Learning, reasoning, and decision making (pp. 379-428). Washington, DC, US: American Psychological Association.

Gillmore, M. R., Archibald, M. E., Morrison, D. M., Wilsdon, A.W, Elizabeth A. H., \& Marilyn J. (2002). Teen sexual behavior: applicability of the theory of reasoned action. Journal of Marriage and the Family, 64, 885- 897.

Halpern-Flesher, B., Kropp, R., \& Boyer, C. (2014). Adolescents' self-efficacy to communicate about sex: Its role in condom attitudes commitment and use. Adolescence, 39, 443-456.

Hardcastle, M. (2012). Beating peer pressure your guide to teen advise. California: Advice Book. Discussion Paper No. 7683. The Institute for the Study of Labor (IZA) in Bonn.

Hollander, D. (2010). Perceptions of peer behavior predict whether Peruvian adolescents have had sex. Family Planning Perspective, 27, 154-161.

Jones, N., \& Espey, J. (2008). Increasing visibility and promoting policy action to tackle sexual exploitation in and around schools in Africa. A briefing paper with a focus on West Africa. Dakar: Plan West Africa.

Jones, V., Lenehan, C., \& Robinson, C. (2010). Stronger links: A guide to good practice for children's family based short-term care service. Bristol: University of Bristol, Policy Press.

Kawaguchi, H. (2004). Peer effects on substance use among American teenagers. Population Economics, 2, 351-367. 
Kellie, B., \& Gormly, A. (2013). Peer pressure for students and adults can be positive. Pittsburgh Tribune

Review. http://www.agrange.edu/responses/pdf/citations/nursing/adolscents\%20selfesteem.pdf.

Lagana, L. (2009). Psychosocial correlates of contraceptive practices during late adolescence. Adolescence, 34, 463-82.

Mlyakado, B. P. (2013). Attitudes and views of teachers towards students' sexual relationships in secondary schools in Tanzania. Academic Research International, 4(1), 232-241.

Moore, M., \& Rosenthal, G. (2006). Sexuality in adolescence: Current trends. New York, NY: Routledge Publishing.

Muratore, I. (2008). Teenagers, blogs and socialization: A case study of young French bloggers. Young Consumers, 9(2), 131-142.

Nwoke. E. A, Okafor J. O., \& Nwankwo B. O. (2012). Socio-demographic correlates of sexual behaviors: A cross sectional survey of adolescents in Imo State secondary schools. Journal of Public Health and Epidemiology, 4(4), 88-92.

Ogungbamila, A. (2013). Demographic predictors of premarital sexual behaviors among undergraduates. Nigerian Journal of Applied Behavioral Sciences, 1, 68-74.

Ogunsola, M. O. (2011). The effect of premarital cohabitation on quality of relationship and marital stability of married people in Southwest, Nigeria. African Nebula, 3, 16-24.

Olugbenga-Bello, A. I., Adebimpe, W. O., \& Abodunrin, O. L. (2009). Sexual risk behavior among inschool adolescents in public secondary schools in a southwestern city in Nigeria. International Journal of Health Research, 2(3), 243-251.

Prinstein, M., Meade, C., \& Cohen, G. (2013). Adolescent oral sex peer popularity and perceptions of best friends' sexual behavior. Perception Psychology, 28, 243-249.

Rena, R. (2013). Premarital sex-lessons from American experience. The Nigerian Journal of Guidance and Counselling 11(1), 134-155.

Research Advisor (2006). Required sample size. Retrieved from http//www google.com.

Sieving, R., Eisenberg, M., \& Pettingell, S. (2011). Friends' influence on adolescents' first sexual intercourse. Perspectives Sex Reproductive Health, 38, 13-9.

Smith, J. (2009). Making reproductive health service youth friendly research program and policies series. In L. Steinberg (Eds.), Handbook of Adolescent Psychology, 1, 723-763.

Smylie, L., Medaglia, S., \& Maticka-Tyndale, E. (2006). The effect of social capital and sociodemographics on adolescent risk and sexual health behaviors. The Canadian Journal of Human Sexuality, 15(2), 95-112.

Steinberg, L., \& Monahan, K. C. (2007). Age differences in resistance to peer influence. Developmental Psychology, 43, 1531-1543.

Wang, X., Chunling Y., \& Yujie, W. (2012). Social media peer communication and impacts on purchase intentions: A consumer socialization framework. Journal of Interactive Marketing, 26, 198208. 